\title{
INFLUENCE OF POMEGRANATE JUICE ON THE CYP3A4- MEDIATED METABOLISM AND P-GLYCOPROTEIN MEDIATED TRANSPORT OF SAQUINAVIR IN VIVO AND EX VIVO MODELS
}

\author{
Sridhar Vemulapalli, Surya Sandeep Mullapudi, Ravindrababu Pingili, Ramya \\ Kothapalli, Sivaramakrishna Kondru, Naveenbabu Kilaru*
}

Department of

Pharmacology, KVSR

Siddhartha College of Pharmaceutical Sciences, Vijayawada, Andhra Pradesh, India-520010.

Submitted: 01-05-2016

Revised: $15-06-2016$

Accepted: 25-08-2016

*Corresponding author

Naveenbabu Kilaru

Email:

naveenbabukvsr@gmail.com

\begin{abstract}
Cytochrome P450 3A4 (CYP3A4) and P-glycoprotein (P-gp) play an important role in the first pass metabolism thereby limits the oral bioavailability of many clinically important and frequently prescribed drugs. The absolute oral bioavailability of saquinavir is very low (i. e. $4 \%$ ) due to its extensive first pass metabolism by the major metabolizing isozyme CYP3A4 and it is also a substrate of P-gp. Pomegranate juice (PGJ) was known to be a modulator of CYP3A4 and P-gp. Therefore, the aim of this study was to evaluate the influence of PGJ on the pharmacokinetics (PK) of saquinavir in wistar rats and on the P-gp mediated intestinal transport of saquinavir in everted gut sacs ex vivo. Rats were treated orally with saquinavir $(100 \mathrm{mg} / \mathrm{kg})$ alone and in combination with PG] $(0.5,1.0$ and $2.0 \mathrm{~mL} / 200 \mathrm{~g}$, BW) for 15 consecutive days. Blood samples were collected on $1^{\text {st }}$ day in single dose pharmacokinetic study (SDS) and on $15^{\text {th }}$ day in multiple dose pharmacokinetic study (MDS). The peak plasma concentration $\left(\mathrm{C}_{\max }\right)$ and area under the plasma concentrationtime curve $\left(\mathrm{AUC}_{0-24}\right)$ of saquinavir was increased with $\mathrm{PGJ}$ in SDS $(p<0.001)$ may be due to inhibition of CYP3A4 and P-gp. But interestingly, the $\mathrm{C}_{\max }$ and $\mathrm{AUC}_{0-24}$ of saquinavir was decreased significantly with PGJ in MDS. This is may be due to induction of CYP3A4. The transport of saquinavir was increased in presence of PGJ and known P-gp inhibitors (Verapamil, Ketoconazole and Quinindine) across the rat everted gut sacs ex vivo. The present study results suggested that PG] has both effects (inhibition, in SDS and induction, in MDS) on CYP3A4-mediated saquinavir metabolism in vivo and inhibitory effect on the P-gp mediated intestinal transport of saquinavir ex vivo. Further studies are needed to confirm this interaction at cellular level using cell lines and in humans.
\end{abstract}

Key words: CYP3A4, P-glycoprotein, Everted gut sacs, Pomegranate juice, Pharmacokinetics

\section{INTRODUCTION}

Oral bioavailability of pharmacologically effective drugs is often limited by first-pass metabolism. P-glycoprotein (P-gp) and cytochrome P450 (CYP) enzymes play an important role in limiting the bioavailability (BA) of orally administered drugs (Wahajuddin et al., 2014; Neirinckx et al., 2010; Wacher et al., 1998). Incomplete oral BA could be due to poor intestinal absorption caused by P-gp or metabolism by CYP enzymes in the intestinal membrane or within the gastrointestinal (GI) lumen, or presystemic hepatic extraction (Letendre et al., 2004; Martin et al., 2002; Kenneth et al., 1997).

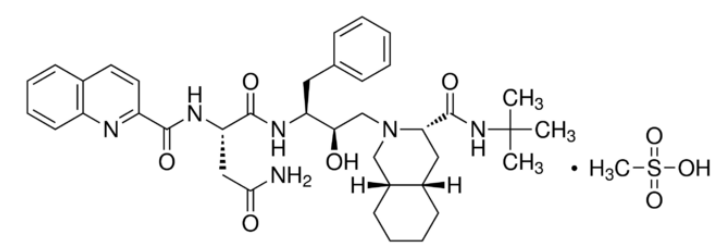

Figure 1. Structure of Saquinavir Mesylate

Saquinavir mesylate (Figure 1) is an antiretroviral protease inhibitor, used for the treatment of human immunodeficiency virus (HIV) infection and it was the first protease inhibitor approved by the Food and drug administration (Brian et al., 2013; Dan et al., 
2012; Joseph et al., 2009). It undergoes extensive first-pass metabolism by CYP3A4 in the gastrointestinal tract (GIT) and the liver. It is a substrate of P-gp and CYP3A4; these two systems critically limit its bioavailability (Doherty et al., 2002; Hall et al., 1999; Eagling et al., 1997; Doherty et al., 1997). Only about $0.7 \%$ of an oral dose will reach the systemic circulation when saquinavir is taken without food (Kupferschmidt et al., 1998) and 4\% when taken with food (Noble et al., 1996). The low bioavailability is thought to be due to a combination of incomplete absorption and extensive first-pass metabolism.

Pomegranate (Punica granatum L.) is an edible fruit that is consumed fresh and in processed forms, such as juice, wines, and extracts. Pomegranate has been used for centuries in ancient cultures for its medicinal purposes, and numerous studies have suggested its health effects (Basu et al., 2009; Jurenka et al., 2008). The pomegranate juice was composed of fructose $(\mathrm{g} / 100 \mathrm{~g})$ 6.83 \pm 0.50 ; glucose $(\mathrm{g} / 100 \mathrm{~g})$ $6.66 \pm 0.44$; sucrose $(\mathrm{g} / 100 \mathrm{~g}) 0.00 \pm 0.00$; sorbitol $(\mathrm{g} / 100 \mathrm{~g}) \quad 0.00 \pm 0.01$; acidity $(\mathrm{g} / 100 \mathrm{~g}$ as citric acid) $1.25 \pm 0.32$; citric acid (g/100 g) $1.19 \pm 0.30$; malic acid $(\mathrm{g} / 100 \mathrm{~g}) 0.065 \pm 0.034$; tartaric acid $(\mathrm{g} / 100 \mathrm{~g}) \quad 0.00 \pm 0.00$; isocitric acid $(\mathrm{mg} / \mathrm{kg})$ 63 \pm 21 ; potassium $(\mathrm{mg} / \mathrm{kg}) 2320 \pm 400$; proline $(\mathrm{mg} / \mathrm{kg}) 7 \pm 5$; formol value [milliequivalents/ $100 \mathrm{~g}] 1.00 \pm 0.24 ; 13 \mathrm{C} / 12 \mathrm{C}$ ratio $[\mathrm{o} / \mathrm{oo}$ Pee Dee belemnite]-26.4 \pm 0.8 ; delphinidin-3,5diglucoside; delphinidin-3-glucoside; cyanidin3,5-diglucoside; cyanidin-3-glucoside; pelargonidin-3,5-diglucoside and pelargonidin-3-glucoside (Krueger et al., 2012). Pomegranate juice has been proposed as an anti-HIV-1 (Neurath et al., 2005), antioxidant (Michael et al., 2005), chemopreventive, chemotherapeutic (Bell et al., 2008) anti-atherosclerotic and antiinflammatory agent (Lansky et al., 2007). Pomegranate juice was also reported as modulator of CYP3A4 (Farkas et al., 2007; Hidaka et al., 2005), CYP2C9 (Nagata et al., 2002) and CYP1A2 (Faria et al., 2007). However, whether the repeated coadministration of pomegranate juice could alter the pharmacokinetics of saquinavir or not is still unknown. Therefore, the aim of this study was to evaluate the influence of PGJ on the pharmacokinetics (PK) of saquinavir in wistar rats and on the P-gp mediated intestinal transport of saquinavir in everted gut sacs $e x$ vivo.

\section{MATERIALS AND METHODS Drugs and chemicals}

Saquinavir was gifted by Manus Aktteva Biopharma LLP (Ahmedabad, India). Pomegranate fresh fruits were purchased from local market and made juice before administration. Ketoconazole, quinidine and verapamil were obtained from Mylan Pharmaceuticals Ltd and Sipra Labs Ltd (Hyderabad, India) respectively. Acetonitrile, water of high-performance liquid chromatography (HPLC) grade, sodium carboxymethyl cellulose (SCMC) were purchased from Finar chemicals Ltd (Ahmedabad, India). All other chemicals and reagents used were of analytical grade.

\section{Experimental Animals}

Animal experiments were performed after the protocols approved by the animal ethics committee of KVSR Siddhartha College of Pharmaceutical Sciences (SCOPS), Vijayawada, India. KVSR SCOPS is registered (993/a/06/CPCSEA) by the Committee for the Purpose of Control and Supervision of Experiments on Animals (CPCSEA), Govt. of India. Male wistar rats (180-220g) were procured from Mahaveer Enterprises, Hyderabad, India. Animals were housed six per cage, fed with standard pellet diet (Hindustan Lever, India) and water ad libitum. Animals were kept under standard laboratory conditions (12/12h light/ darkness, $25 \pm 2^{\circ} \mathrm{C}$, and $50-60 \%$ humidity) before and during the experiment.

\section{Experimental Protocol}

The study was divided into three experiments as it has been described previously by Sridhar et al. (2014) and Ravindra et al. (2013). First two experiments are single dose pharmacokinetic study (SDS) and multiple dose pharmacokinetic study (MDS) in vivo. The third experiment was conducted on rat everted gut sacs to determine the role of P-gp in the transport of saquinavir ex vivo. The doses of saquinavir and pomegranate juice were selected based upon the observations from the earlier experiments. 
Effect of pomegranate juice on the pharmacokinetics of saquinavir in vivo (SDS and MDS)

Wistar rats were randomly divided into four groups of six animals in each group. The rats were treated orally with the following drugs once daily for 15 consecutive days:

Group I: Saquinavir (100mg/kg); Group II: Pomegranate juice $(0.5 \mathrm{~mL} / 200 \mathrm{~g}$ BW. $)+$ Saquinavir (100mg/kg); Group III: Pomegranate juice $(1 \mathrm{~mL} / 200 \mathrm{gBW})+$ Saquinavir $(100 \mathrm{mg} / \mathrm{kg})$; Group IV: Pomegranate juice (2mL/200g BW) + Saquinavir $(100 \mathrm{mg} / \mathrm{kg})$.

After treatment, $150 \mu \mathrm{L}$ blood samples were collected in citrated eppendorf tubes (Tarsons, Kolkata, India) from retro-orbital venous plexus (Shih et al., 2005) at 1.0, 2.0, $2.5,3.0,3.5,4.0,4.5,6.0,8.0,10.012 .0$ and $24.0 \mathrm{~h}$ under slight ether anesthesia on the $1^{\text {st }}$ day in SDS and on the $15^{\text {th }}$ day in MDS. The blood samples were centrifuged (Remi, R- 4C Compact model, Mumbai, India) at $6000 \mathrm{rpm}$ for $10 \mathrm{~min}$ and plasma stored at $-20^{\circ} \mathrm{C}$ (Remi $-20^{\circ} \mathrm{C}$ freezer, India) until analysis.

\section{Extraction of saquinavir from plasma}

The liquid-liquid extraction procedure was used to extract saquinavir from the rat plasma by the method described by Shriram et al. (2007) and Harumi et al. (2001). To an aliquot of $10 \mu \mathrm{L}$ plasma, $250 \mu \mathrm{L}$ of sodium hydroxide $(0.1 \mathrm{~N})$ was added and $\mathrm{pH}$ adjusted to 10 with hydrochloric acid. The mixture was vortex-mixed for $2 \mathrm{~min}$ on a REMI vortex mixer (Mumbai, India) and to this $4 \mathrm{~mL}$ of extraction solvent (Methyl tertiary butyl ether: dichloromethane $(90: 10, \mathrm{v} / \mathrm{v}))$ was added and vortexed for $10 \mathrm{~min}$. After centrifugation at $6000 \mathrm{rpm}$ for $5 \mathrm{~min}$, the supernatant $(1 \mathrm{~mL})$ was dried under gentle stream of nitrogen at $40^{\circ} \mathrm{C}$. The dry residue was reconstituted in $200 \mu \mathrm{L}$ of the mobile phase, then vortex-mixed. A $20-\mu \mathrm{L}$ aliquot of the resulting solution was injected onto high performance liquid chromatography (HPLC) system for analysis.

\section{Determination of Saquinavir by HPLC}

Saquinavir concentrations in plasma were estimated by reverse phase-HPLC (RPHPLC) as it has been described previously by Huy et al. (1997) and Frappier et al. (1998) with minor modification. A Shimazdu HPLC system consisted of a pump (LC-20AT VP), C 18 column (ODS Thermo Hypersil, 150x4.6mm, $5.0 \mu \mathrm{m}$, Thermo Electron Corp, USA) and a dual wavelength UV-visible detector (SPD-10A VP). LC solution software was used to collect and process the data. The composition of the mobile phase was acetonitrile: water (50:50, $\mathrm{v} / \mathrm{v})$. The mobile phase was vacuum-filtered through $0.45 \mu \mathrm{m}$ nylon membranes filters, and degassed by ultrasonication for $20 \mathrm{~min}$ before use. The mobile phase flow was set at $1.0 \mathrm{~mL} / \mathrm{min}$ and the injection volume was $20 \mu \mathrm{L}$. After equilibration with the solvent to obtain a stable baseline, aliquots of samples were injected. The total run time was set at 5 min. The absorbance of the eluent was monitored at $240 \mathrm{~nm}$. All the analyses were performed at $25.0 \pm 0.5^{\circ} \mathrm{C}$.

\section{Preparation of stock and standard solutions}

Stock solution $(100 \mu \mathrm{g} / \mathrm{mL})$ of saquinavir was prepared by dissolving the appropriate amount of saquinavir in methanol-water (50:50, $\mathrm{v} / \mathrm{v})$ and stored at $-20^{\circ} \mathrm{C}$ until analysis. The calibration standards were prepared by dilution of the stock solutions with blank (drug-free) plasma to obtain the desired concentrations ranges of $0.5-20 \mu \mathrm{g} / \mathrm{mL}$. An aliquot of $20 \mu \mathrm{L}$ was injected onto the HPLC system and the retention times for plasma and saquinavir were obtained at 1.287 and $3.703 \mathrm{~min}$, respectively (Figure 2).

\section{Effect of pomegranate juice on the P-gp mediated transport of saquinavir ex vivo}

Everted sacs of rat ileum were prepared using a method described before by Ravindra et al. (2013) and Sridhar et al. (2014) in our laboratory. Male wistar rats weighing about 180-200g were deprived of food for 1 day before the experiments, with double-distilled water available ad libitum. The rats were anesthetized with ether and the distal ileum of the rat intestine (approximately $10 \mathrm{~cm}$ each) was dissected. Each intestinal segment was immediately rinsed in ice-cold Krebs-RingerHensleit (KRH) bicarbonate buffer $(7.8 \mathrm{~g} \mathrm{NaCl}$, $0.35 \mathrm{~g} \mathrm{KCl}, 0.37 \mathrm{~g} \mathrm{CaCl}_{2}, 1.37 \mathrm{~g} \mathrm{NaHCO}, 0.32 \mathrm{~g}$ $\mathrm{NaH}_{2} \mathrm{PO}_{4}, 0.02 \mathrm{~g} \mathrm{MgCl}$, $1.4 \mathrm{~g}$ glucose, $\mathrm{pH}$ 6.8). 

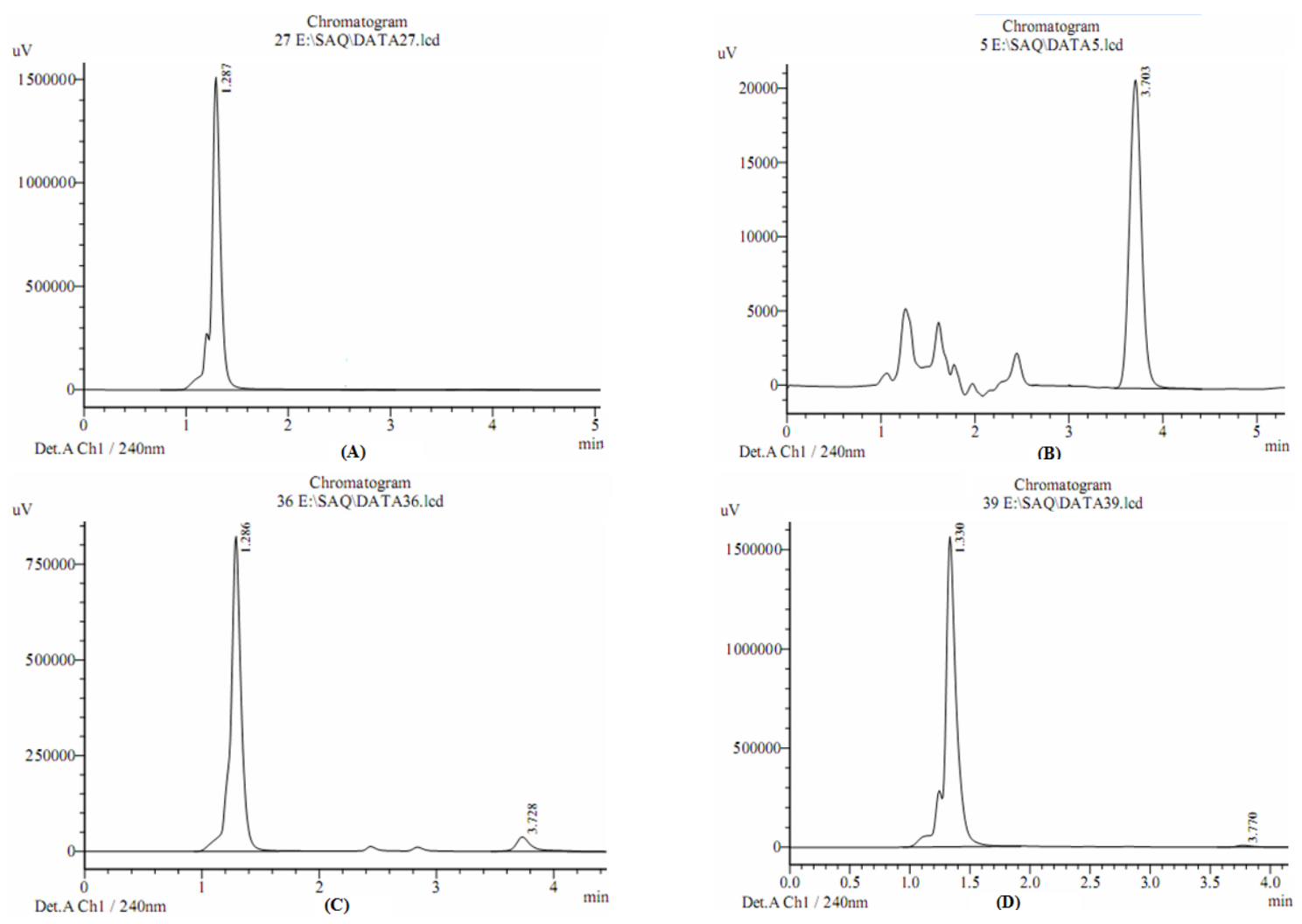

Figure 2. Representative Chromatograms of (a) Plasma blank (1.287); (b) Saquinavir $10 \mu \mathrm{g} / \mathrm{mL}$ (3.701); (c) Plasma + Saquinavir $1 \mu \mathrm{g} / \mathrm{mL}$ and (d) plasma sample from a rat receiving $100 \mathrm{mg} / \mathrm{kg}$ saquinavir monitored at $240 \mathrm{~nm}$.

The intestinal segments were everted using a stain less steel rod and one end was ligated. The open end of the everted sac was ligated after the insertion of a polyethylene tube. After the everted sac was filled with $1 \mathrm{~mL}$ of $\mathrm{KRH}$ buffer, placed in $30 \mathrm{~mL}$ of $\mathrm{KRH}$ buffer gassed with $\mathrm{O}_{2} / \mathrm{CO}_{2}(95: 5)$ at $37^{\circ} \mathrm{C}$ for $30 \mathrm{~min}$. About $100 \mu \mathrm{g} / \mathrm{mL}$ of saquinavir was added to the mucosal side and aliquots $(150 \mu \mathrm{L})$ of serosal fluid were collected at 10,20,30,40,50 and $60 \mathrm{~min}$. The same volume of buffer was replaced at each time point. The intestinal absorption of saquinavir in the absence and presence of pomegranate juice and standard PgP and CYP3A4 inhibitors (verapamil, ketoconazole and quinidine, $50 \mu \mathrm{g} / \mathrm{mL}$ ) was also determined by using the above method. At the end of incubation all samples were centrifuged at $3500 \mathrm{rpm}$ for $10 \mathrm{~min}$ and supernatants was used RP-HPLC analysis.

\section{Calculation of pharmacokinetic parameters}

The plasma concentrations versus time data for saquinavir obtained from each individual rat were submitted to a non-compartmental pharmacokinetic analysis using Thermo Kinetica (Version 5.1, Thermo Electron Corporation, USA) pharmacokinetics fitting software to calculate the model-independent pharmacokinetic parameters. These parameters were the area under the plasma concentration-time curve (AUC) from time zero to the last sampling time $\left(\mathrm{AUC}_{0-\mathrm{t}}\right)$, AUC from time zero to infinite $\left(\mathrm{AUC}_{0-\alpha}\right)$, apparent terminal half-life $\left(\mathrm{t}_{1 / 2}\right)$, clearance $(\mathrm{CL} / \mathrm{F})$, apparent volume of distribution $\left(\mathrm{V}_{\mathrm{z}} / \mathrm{F}\right)$, apparent volume of distribution at steady state $\left(\mathrm{V}_{\mathrm{ss}}\right)$ and mean residence time (MRT). Maximum plasma concentrations $\left(\mathrm{C}_{\max }\right)$ and times to achieve maximum plasma concentrations $\left(T_{\max }\right)$ were obtained directly from the individual plasma concentration-time curves. 

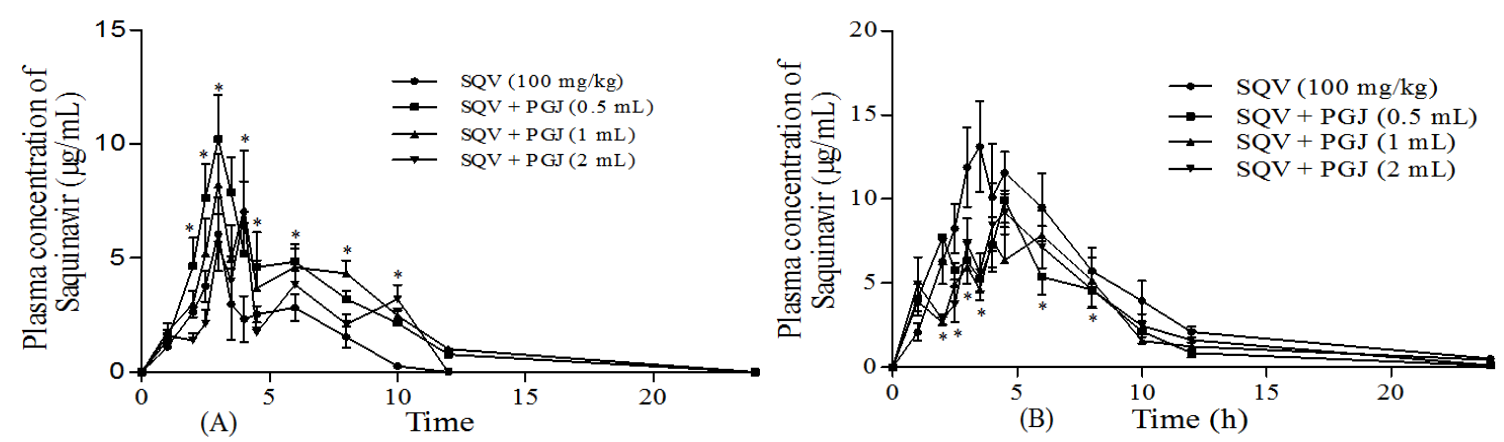

Figure 3. Mean plasma concentration-time profiles of saquinavir $(100 \mathrm{mg} / \mathrm{kg})$ following an oral administration of saquinavir to rats with or without pomegranate juice (A) on $1^{\text {st }}$ day; (B) on $15^{\text {th }}$ day $(\mathrm{n}=6)$. ( $\bullet$ Control (saquinavir alone), $(\mathbf{\square})$ with pomegranate juice $(0.5 \mathrm{~mL} / 200 \mathrm{~g}$ b.w.), $(\mathbf{\Lambda})$ with pomegranate juice $(1 \mathrm{~mL} / 200 \mathrm{~g}$ b.w.), $(\boldsymbol{\nabla})$ with pomegranate juice $(2 \mathrm{~mL} / 200 \mathrm{~g}$ b.w.). All values are Mean $\pm \mathrm{SD}$. Bars represent the standard deviation. ${ }^{*} p<0.001$, when compared to saquinavir control group. SQV, Saquinavir; PGJ, Pomegranate juice. (Two-way ANOVA followed by Bonferroni post-tests to compare to each column to column).

\section{Statistical analysis}

All statistics were calculated using Graph Pad Prism 5.0 software (San Diego, CA, USA). Pharmacokinetic parameters and plasma concentrations of saquinavir for groups were compared using two-way ANOVA followed by Bonferroni post-tests to compare to each column to column. Ex vivo data analysed by one-way ANOVA followed by Dunnett's post hoc test. The $p$ value less than 0.05 were considered significant.

\section{RESULTS AND DISCUSSION Effect of pomegranate juice on the pharmacokinetics of saquinavir in SDS}

The plasma concentration-time profiles of saquinavir after the oral administration of the saquinavir alone $(100 \mathrm{mg} / \mathrm{kg})$ and in combination with pomegranate juice $(0.5,1.0$, and $2.0 \mathrm{~mL} / 200 \mathrm{~g} \mathrm{BW}$ ) in SDS (Figure $3(\mathrm{~A})$ ). When saquinavir was co-administered with pomegranate juice, the plasma concentrations of saquinavir were significantly increased compared to the saquinavir alone group (Fig. $3 \mathrm{~A})$. The mean pharmacokinetic parameters of saquinavir in plasma (Table I). The $\mathrm{C}_{\max }$ of saquinavir was significantly increased from $5.852 \pm 1.282$ to $10.205 \pm 1.645$ and $8.473 \pm 1.568$ $\mu \mathrm{g} / \mathrm{mL}$ when co-administered with pomegranate juice $0.5 \mathrm{~mL}$ and $1.0 \mathrm{~mL} / 200 \mathrm{~g}$, respectively. The $\mathrm{AUC}_{0-\infty}$ of saquinavir was increased from $21.591 \pm 3.155$ to $49.741 \pm 4.620$ (with pomegranate juice $0.5 \mathrm{~mL}$ ), and $53.936 \pm 3.120 \mathrm{ig}$. $\mathrm{h} / \mathrm{mL}$ (with pomegranate juice $2.0 \mathrm{~mL}$ ). The $\mathrm{t}_{1 / 2}$ of saquinavir after pomegranate juice treatment was longer than saquinavir alone group $(p<0.01)$. The MRT of saquinavir was increased from $4.683 \pm 0.841$ to $8.423 \pm 2.312 \mathrm{~h}$ when coadministered with pomegranate juice $(2 \mathrm{~mL} /$ 200g). The CL/F, V $/ F$, and $V_{s s} / F$ of saquinavir were significantly decreased by pomegranate juice.

\section{Effect of pomegranate juice on the pharmacokinetics of saquinavir in MDS}

Figure 3B shows the mean plasma concentration-time data obtained after oral administration of saquinavir $(100 \mathrm{mg} / \mathrm{kg}$ ) alone and in combination with pomegranate juice for 15 consecutive days in rats. Plasma concentrations of saquinavir were significantly decreased in the rats treated with pomegranate juice. The $\mathrm{C}_{\max }$ of saquinavir decreased significantly from $12.352 \pm 1.361$ to $7.595 \pm 2.624$ (with $1.0 \mathrm{~mL}$, pomegranate juice) and $8.336 \pm 1.582 \mu \mathrm{g} / \mathrm{mL}$ (with $2.0 \mathrm{~mL}$, pomegranate juice). Pomegranate juice co-administration for 15 consecutive days significantly decreased the $\mathrm{AUC}_{0-\infty}$ of saquinavir from $98.091 \pm 5.260$ to $59.661 \pm 4.281$ (with $0.5 \mathrm{~mL}$, pomegranate juice) and $64.217 \pm 5.362 \mu \mathrm{g}$. $\mathrm{h} / \mathrm{mL}$ (with $2.0 \mathrm{~mL}$, pomegranate juice). The $t_{1 / 2}$ of saquinavir was shorter when used with pomegranate juice. 


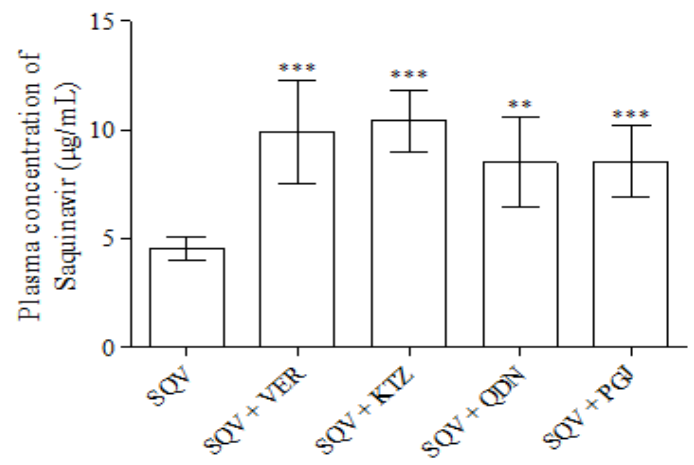

Figure 4. The transport of saquinavir $(100 \mu \mathrm{g} / \mathrm{mL})$ from mucosal to serosal side in the absence and presence of verapamil, quinidine, ketoconazole $(50 \mu \mathrm{g} / \mathrm{mL})$ and pomegranate juice $(0.5 \mathrm{~mL} / \mathrm{sac})$. SQV: Saquinavir; VER: Verapamil; QDN: Quinidine; KTZ: Ketoconazole; PGJ, Pomegranate juice. The data represent the mean \pm S.D. $(n=3) .{ }^{*} p<0.001$ significantly different compared to saquinavir group.

Table I. Pharmacokinetic parameters of saquinavir after the oral administration of saquinavir $(100 \mathrm{mg} / \mathrm{kg})$ to rats in the presence or absence of pomegranate juice $(0.5,1$ and $2 \mathrm{~mL} / 200 \mathrm{~g})$ on $1^{\text {st }}$ day (n =6).

\begin{tabular}{ccccc}
\hline Parameter & SQV & SQV + PGJ (0.5mL) & SQV + PGJ (1mL) & SQV + PGJ (2mL) \\
\hline $\mathrm{C}_{\max }(\mu \mathrm{g} / \mathrm{mL})$ & $5.852 \pm 1.282$ & $10.205 \pm 1.645^{* * *}$ & $8.473 \pm 1.568^{*}$ & $6.425 \pm 1.354^{\mathrm{NS}}$ \\
$\mathrm{AUC}_{0-24}$ & $19.133 \pm 2.951$ & $45.364 \pm 3.451^{* * *}$ & $43.421 \pm 5.326^{* * *}$ & $28.350 \pm 3.547^{* *}$ \\
$(\mu \mathrm{g} . \mathrm{h} / \mathrm{mL})$ & & & & \\
$\mathrm{AUC}_{0-\infty}$ & $21.591 \pm 3.155$ & $49.741 \pm 4.620^{* * *}$ & $45.455 \pm 3.624^{* * *}$ & $53.936 \pm 3.120^{* * *}$ \\
$(\mu \mathrm{g} . \mathrm{h} / \mathrm{mL})$ & & & & \\
$\mathrm{t}_{\max }(\mathrm{h})$ & $3.0 \pm 0$ & $3.0 \pm 0^{\mathrm{NS}}$ & $3.50 \pm 0^{\mathrm{NS}}$ & $4.0 \pm 0^{\mathrm{NS}}$ \\
$\mathrm{t}_{1 / 2}(\mathrm{~h})$ & $1.181 \pm 0.223$ & $2.416 \pm 0.482^{* *}$ & $2.115 \pm 0.561^{* *}$ & $2.256 \pm 0.548^{* *}$ \\
$\mathrm{MRT}(\mathrm{h})$ & $4.683 \pm 0.841$ & $6.754 \pm 1.361^{* * *}$ & $7.248 \pm 1.250^{* * *}$ & $8.423 \pm 2.312^{* *}$ \\
$\mathrm{CL}_{/} \mathrm{F}(\mathrm{mg} / \mathrm{h} / \mathrm{kg})$ & $0.934 \pm 0.210$ & $0.421 \pm 0.112^{\mathrm{NS}}$ & $0.445 \pm 0.102^{\mathrm{NS}}$ & $0.231 \pm 0.025^{* *}$ \\
$\mathrm{~V}_{\mathrm{z}} / \mathrm{F}(\mathrm{mL} / \mathrm{kg})$ & $1.592 \pm 0.436$ & $1.433 \pm 0.335^{\mathrm{NS}}$ & $1.214 \pm 0.348^{\mathrm{NS}}$ & $1.311 \pm 0.213^{\mathrm{NS}}$ \\
$\mathrm{V}_{\mathrm{ss}}(\mathrm{mL} / \mathrm{kg})$ & $4.372 \pm 1.051$ & $2.415 \pm 0.362^{* *}$ & $2.746 \pm 0.695^{* *}$ & $2.860 \pm 0.632^{* *}$ \\
\hline
\end{tabular}

$\mathrm{SQV}$, Saquinavir; PGJ, Pomegranate juice; $\mathrm{AUC}_{0-24}$, Area under the plasma concentration-time curve from $0 \mathrm{~h}$ to $24 \mathrm{~h}$; $\mathrm{AUC}_{0-\infty}$, area under the plasma concentration-time curve from $0 \mathrm{~h}$ to infinity; $\mathrm{C}_{\max }$, peak plasma concentration; $\mathrm{T}_{\max }$, time to reach peak plasma concentration; $\mathrm{t}_{1 / 2}$, terminal half-life; MRT, mean residence time; CL/F, apparent total body clearance or oral clearance; $\mathrm{V}_{\mathrm{z}} / \mathrm{F}$, apparent volume of distribution; Vss, apparent volume of distribution at steady state. All values are Mean $\pm \mathrm{SD} .{ }^{* * *} p<0.001,{ }^{* *} p<0.01,{ }^{*} p<0.05$, $\mathrm{NS}_{p}>0.05$ when compared to rasagiline alone group (Two-way ANOVA followed by Bonferroni post-tests to compare to each column to column).

The saquinavir $\mathrm{t}_{1 / 2}$ was decreased from $4.295 \pm 1.211$ to $2.912 \pm 0.648 \mathrm{~h}$ (with $0.5 \mathrm{~mL}$, pomegranate juice). The MRT of saquinavir also reduced from $7.851 \pm 1.482$ to $6.055 \pm 1.340 \mathrm{~h}$ with co-administration of $0.5 \mathrm{~mL}$ of pomegranate juice. A significant difference was not observed in the apparent total body clearance of saquinavir compared to saquinavir control group (Table II).

\section{Effect of pomegranate juice on the saquinavir absorption ex vivo}

It is known that saquinavir is transported by P-gp present in the intestinal epithelium. To determine the influence of pomegranate juice on the P-gp mediated saquinavir transport, studied its transport activity in-vitro using everted gut sacs. The transport of saquinavir was increased in addition of pomegranate juice 
Table II. Pharmacokinetic parameters of saquinavir after the oral administration of saquinavir $(100 \mathrm{mg} / \mathrm{kg})$ to rats in the presence or absence of pomegranate juice $(0.5,1$ and $2 \mathrm{~mL} / 200 \mathrm{~g})$ on $15^{\text {th }}$ day $(\mathrm{n}=6)$.

\begin{tabular}{ccccc}
\hline Parameter & SQV & SQV+PGJ (0.5mL) & SQV+PGJ (1mL) & SQV+PGJ (2mL) \\
\hline $\mathrm{C}_{\text {max }}(\mu \mathrm{g} / \mathrm{mL})$ & $12.352 \pm 1.361$ & $8.553 \pm 1.688^{* * *}$ & $7.595 \pm 2.624^{* *}$ & $8.336 \pm 1.582^{* *}$ \\
$\mathrm{AUC} \mathrm{C}_{0-24}$ & $93.511 \pm 6.204$ & $60.658 \pm 4.315^{* *}$ & $57.315 \pm 5.300^{* * *}$ & $61.350 \pm 4.627^{* * *}$ \\
$(\mu \mathrm{g} . \mathrm{h} / \mathrm{mL})$ & & & & \\
$\mathrm{AUC} \mathrm{C}_{0-\infty}$ & $98.091 \pm 5.260$ & $59.661 \pm 4.281^{* * *}$ & $65.758 \pm 4.251^{* * *}$ & $64.217 \pm 5.362^{* * *}$ \\
$(\mu \mathrm{g} . \mathrm{h} / \mathrm{mL})$ & & & & \\
$\mathrm{t}_{\max }(\mathrm{h})$ & $3.50 \pm 0$ & $4.50 \pm 0^{\mathrm{NS}}$ & $6.0 \pm 0^{*}$ & $4.50 \pm 0$ \\
$\mathrm{t}_{1 / 2}(\mathrm{~h})$ & $4.295 \pm 1.211$ & $2.912 \pm 0.648^{* *}$ & $3.915 \pm 0.847^{\mathrm{NS}}$ & $3.239 \pm 0.524^{*}$ \\
$\mathrm{MRT}(\mathrm{h})$ & $7.851 \pm 1.482$ & $6.055 \pm 1.340^{*}$ & $7.486 \pm 1.252^{\mathrm{NS}}$ & $6.856 \pm 1.220^{\mathrm{NS}}$ \\
$\mathrm{CL} / \mathrm{F}(\mathrm{mg} / \mathrm{h} / \mathrm{kg})$ & $0.201 \pm 0.012$ & $0.323 \pm 0.011^{\mathrm{NS}}$ & $0.303 \pm 0.011^{\mathrm{NS}}$ & $0.331 \pm 0.012^{\mathrm{NS}}$ \\
$\mathrm{V}_{z} / \mathrm{F}(\mathrm{mL} / \mathrm{kg})$ & $1.265 \pm 0.232$ & $1.434 \pm 0.247 \mathrm{NN}^{\mathrm{NS}}$ & $2.477 \pm 0.345^{* *}$ & $1.427 \pm 0.214 \mathrm{NS}$ \\
$\mathrm{V}_{\mathrm{ss}}(\mathrm{mL} / \mathrm{kg})$ & $1.610 \pm 0.351$ & $2.013 \pm 0.332^{\mathrm{NS}}$ & $2.868 \pm 0.586^{* *}$ & $2.113 \pm 0.632^{\mathrm{NS}}$ \\
\hline
\end{tabular}

$\mathrm{SQV}$, Saquinavir; PGJ, Pomegranate juice; $\mathrm{AUC}_{0-24}$, Area under the plasma concentration-time curve from $0 \mathrm{~h}$ to $24 \mathrm{~h}$; $\mathrm{AUC}_{0-\infty}$, area under the plasma concentration-time curve from $0 \mathrm{~h}$ to infinity; $\mathrm{C}_{\max }$, peak plasma concentration; $T_{\max }$, time to reach peak plasma concentration; $t_{1 / 2}$, terminal half-life; MRT, mean residence time; CL/F, apparent total body clearance or oral clearance; $\mathrm{V}_{\mathrm{z}} / \mathrm{F}$, apparent volume of distribution; Vss, apparent volume of distribution at steady state. All values are Mean \pm SD. ${ }^{* * *} p<0.001,{ }^{* *} p<0.01,{ }^{*} p<0.05$, $\mathrm{NS}_{p}>0.05$ when compared to rasagiline alone group (Two-way ANOVA followed by Bonferroni post-tests to compare to each column to column).

Table III. Transport of saquinavir from the mucosal to serosal side with or without verapamil, ketoconazole, quinidine $(50 \mu \mathrm{g} / \mathrm{mL})$ and pomegranate juice $(0.5 \mathrm{~mL} / \mathrm{sac})$ using everted gut sacs $e x$ vivo ( $\mathrm{n}=3)$.

\begin{tabular}{cccccc}
\hline Time (Min) & SQV & SQV+VER & SQV+KTZ & SQV+QDN & SQV+PGJ \\
\hline 0 & $0 \pm 0$ & $0 \pm 0$ & $0 \pm 0$ & $0 \pm 0$ & $0 \pm 0$ \\
10 & $1.882 \pm 0.632$ & $2.581 \pm 0.695$ & $2.302 \pm 0.614$ & $2.125 \pm 0.584$ & $2.715 \pm 0.572$ \\
20 & $2.415 \pm 0.454$ & $5.223 \pm 1.251^{* *}$ & $4.474 \pm 0.526^{*}$ & $5.917 \pm 1.524^{* * *}$ & $5.203 \pm 1.025^{* *}$ \\
30 & $2.793 \pm 0.265$ & $6.634 \pm 1.342^{* * *}$ & $6.535 \pm 1.840^{* * *}$ & $6.046 \pm 1.236^{* * *}$ & $5.455 \pm 1.614^{* *}$ \\
40 & $3.525 \pm 0.471$ & $7.151 \pm 1.658^{* *}$ & $7.051 \pm 1.205^{* *}$ & $6.374 \pm 1.695^{*}$ & $6.282 \pm 1.110^{* *}$ \\
50 & $4.103 \pm 0.658$ & $8.085 \pm 1.374^{* *}$ & $9.773 \pm 1.966^{* * *}$ & $6.857 \pm 1.248^{*}$ & $8.265 \pm 2.101^{* *}$ \\
60 & $4.561 \pm 0.526$ & $9.913 \pm 2.361^{* * *}$ & $10.426 \pm 1.421^{* * *}$ & $8.521 \pm 2.063^{* *}$ & $8.575 \pm 1.631^{* * *}$ \\
\hline
\end{tabular}

SQV, Saquinavir; VER, Verapamil; KTZ, Ketoconazole; QDN, Quinidine; PGJ, Pomegranate juice. All values are Mean $\pm \mathrm{SD} .{ }^{* * *} p<0.001,{ }^{* *} p<0.01,{ }^{*} p<0.05,{ }^{\mathrm{NS}} p>0.05$ when compared to rasagiline alone group (Two-way ANOVA followed by Bonferroni post-tests to compare to each column to column).

and P-gp inhibitors (verapamil, ketoconazole and quinidine) to the mucosal compartment with time in all groups studied (Table III). Saquinavir transport was significantly enhanced from $4.561 \pm 0.526$ to $9.913 \pm 2.361$ (with verapamil), $10.426 \pm 1.421$ (with ketoconazole), $8.521 \pm 2.063$ (with quinidine) and $8.575 \pm 1.631$ (with pomegranate juice) at the end of $1 \mathrm{~h}$ incubation period. These results suggested that the absorption of saquinavir was increased by pomegranate juice may be due to P-gp inhibition (Figure 4).

Absorption is a complex multifactorial phase in pharmacokinetics, and one of the determinants of the clinical outcomes of drug therapy. One of the major obstacles to drug absorption is intestinal metabolism by CYP3A4 (Huang et al., 2008; Yang et al., 2007; Beverly et al., 2006). CYP3A4 is the most important drugmetabolizing enzyme and metabolizes many 
drugs. It is most abundant on the apex of mature enterocytes and is mainly situated in the villous tips of the upper and middle third of the intestine (Genser et al., 2008; Undevia et al., 2005). The enzymes of CYP3A4 expressed in liver and intestine are structurally identical. In addition to CYP3A4 in the intestinal epithelium, an efflux transporter (P-gp) can play a role in altering the bioavailability and pharmacokinetic profiles of substrates (Ho et al., 2005; Chandra et al., 2004). P-gp mediated efflux across the apical membrane (facing the intestinal lumen) and CYP3A4-mediated metabolism in the endoplasmic reticulum of enterocytes can affect the rate and amount of compound that diffuses across the basolateral membrane and enters the bloodstream. CYP3A4 shares many substrates with P-gp (Paine et al., 2006; Paine et al., 1997).

Saquinavir is one of the most widely prescribed agents in the treatment of acquired immunodeficiency syndrome (AIDS), but the oral bioavailability is low (Holladay et al., 2001; Williams et al., 1992). One contributing factor to the low and variable oral bioavailability of saquinavir is extensive and variable first-pass metabolism by CYP3A4. The relative contributions by hepatic and intestinal CYP3A4 to the first-pass metabolism of saquinavir are not known (Stephane et al., 2004). Saquinavir is substrate ofCYP3A4 and P-gp thereby inhibition of CYP3A4-mediated first-pass metabolism is the presumed primary mechanism underlying the significant increase in saquinavir systemic exposure when saquinavir is administered in combination with the known potent CYP3A4 inhibitors. Pazopanib is an inhibitor of CYP3A4 and vemurafenib is a P-gp inhibitor, which increased the serum concentrations of saquinavir when given concomitantly, thus increased the risk of drug toxicity and proarrhythmic effects (Eberl et al., 2007; Lee et al., 1998). Many drug interactions have been reported between saquinavir and CYP3A4 and P-gp inhibitors (azithromycin, sorafenib, ritonavir, nelfinavir, ketoconazole, calcium channel blockers, telithromycin and quinidine).

Pomegranate juice is known to be a potent inhibitor of CYP3A4. Swathi et al. (2012) reported that pomegranate juice increased the $\mathrm{C}_{\max }$ of nitrendipine from $1.93 \pm$
0.18 to $7.92 \pm 1.39(\mu \mathrm{g} / \mathrm{mL})$ and $\mathrm{AUC}_{\text {total }}$ from $10.32 \pm 0.77$ to $51.57 \pm 4.56(\mu \mathrm{g} / \mathrm{h} / \mathrm{mL})$ due to inhibition of CYP3A4-mediated nitrendipine metabolism in rats. In another study, the $\mathrm{C}_{\max }$ and AUC of carbamazepine (CYP3A4 substrate) were significantly increased by pomegranate juice co-administration in rats (Muneaki et al., 2005). The $C_{\max }$ of buspirone(CYP3A4 substrate) was increased by 4.998 -fold, $\mathrm{AUC}_{0-\infty}$ increased by 5.109 -fold. AUC $0-24$ increased by 4.892 -fold, $\mathrm{t}^{1 / 2}$ increased by 1.304 -fold and $\mathrm{T}_{\max }$ increased by 1.197 -folds after pretreatment with pomegranate juice (Shravan et al., 2011). In the present study, the $\mathrm{C}_{\max }$ of saquinavir was increased by 1.734-fold (with $0.5 \mathrm{~mL}$, pomegranate juice) and 1.447-folds (with 1.0 $\mathrm{mL}$, pomegranate juice) when saquinavir was co-administered with pomegranate juice on the $1^{\text {st }}$ day. The $\mathrm{AUC}_{0-24}$ of saquinavir was also increased by 2.370 -folds with pomegranate juice treatment. The intestinal transport of saquinavir was also significantly increased by 1.880 -folds with pomegranate in the everted gut sacs ex vivo. The present study results suggested that pomegranate juice enhanced the systemic exposure of saquinavir by inhibition of CYP3A4-mediated metabolism in SDS and Pgp mediated efflux ex vivo.

Adukondalu et al. (2010) reported that pomegranate juice has induction effect on the CYP3A4 enzymes thereby decreased the plasma concentrations of carbamazepine in rats. In the present study, pomegranate juice also decreased the $\mathrm{C}_{\max }$ and AUC of saquinavir when co-administered with saquinavir for 15 consecutive days $(\mathrm{p}<0.01)$. This is may be due to induction of CYP3A4-mediated saquinavir metabolism by pomegranate juice.

\section{CONCLUSION}

The present study results suggested that PGJ has both effects (inhibition, in SDS and induction, in MDS) on CYP3A4-mediated saquinavir metabolism in vivo and inhibitory effect on the P-gp mediated intestinal transport of saquinavir ex vivo. Further studies are needed to identify the active components in pomegranate juice and evaluate their effects on CYP3A4 and P-gp over expressed cell lines and in humans. 


\section{ACKNOWLEDGEMENTS}

This study was supported by Siddhartha Academy of General and Technical Education (SAGTE). The authors are grateful to $\mathrm{N}$. Venkateswarlu, President and P. Lakshmana Rao, Secretary of SAGTE for providing necessary facilities. The authors thank Dr. G. Devalarao, Pricipal and Dr. Buchi. N. Nalluri, Director for PG studies and Research of KVSR Siddhartha College of Pharmaceutical Sciences, Vijayawada for their encouragement. The authors are grateful for the generous gifts of Ketoconazole, Quinidine, Verapamil and Saquinavir from Mylan Pharmaceutical products, Hyderabad, India and Aktteva Biopharma LLP, Ahmedabad, India, respectively.

\section{REFERENCES}

Adukondalu D., Shravan KY., Vamshi VY., Shiva KR., Madhusudan RY., 2010. Effect of pomegranate juice pretreatment on the transport of carbamazepine across rat intestine. Daru.18: 254-259.

Basu A., Penugonda K., 2009. Pomegranate juice: a heart-healthy fruit juice. Nutr Rev. 67: 49-56.

Bell C, Hawthorne S., 2008. Ellagic acid, pomegranate and prostate cancer-a mini review. I Pharm Pharmacol. 60: 139144.

Beverly K., Matthew T., Dhiren RT., 2006. Deconvoluting the effects of Pglycoprotein on intestinal CYP3A: a major challenge. Current Opinion in Pharmacology. 6: 528-532.

Brian KA., Pamala AJ., Robin LC., Wayne AK., Michael EE., Bradley RW., Joseph GB., 2013. Koda-Kimble and Young's applied therapeutics: The clinical use of drugs. Philadelphia: Lippincott Williams \& Wilkins-Wolters Kluwer, United States of America.

Chandra P., Brouwer KL., 2004. The complexities of hepatic drug transport: current knowledge and emerging concepts. Pharm Res. 21: 719-735.

Dan LL., Anthony SF., Dennis LK., Stephen LH., Jameson JL., Joseph L., 2012. Harrison's Principles of Internal
Medicine. New York: McGraw-Hill Medical, United States of America.

Doherty MM., Charman WN., 2002. The mucosa of the small intestine: how clinically relevant as an organ of drug metabolism? Clin Pharmacokinet. 41: 235253.

Doherty MM., Pang KS., 1997. First-pass effect: significance of the intestine for absorption and metabolism. Drug Chem Toxicol. 20: 329-344.

Eagling VA., Back DJ., Barry MG., 1997. Differential inhibition of cytochrome P450 isoforms by the protease inhibitors, ritonavir, saquinavir, and indinavir. $\mathrm{Br} J$ Clin Pharmacol. 44: 190-194.

Eberl S., Renner B., Neubert A., 2007. Role of p-glycoprotein inhibition for drug interactions: evidence from in vitro and pharmacoepidemiological studies. Clin Pharmacokinet. 46: 1039-1049.

Faria A., Monteiro R., Azevedo I., Calhau C., 2007. Pomegranate juice effects on cytochrome P450S expression: in vivo studies. J Med Food. 10: 643-649.

Farkas D., Oleson LE., Zhao Y., 2007. Pomegranate juice does not impair clearance of oral or intravenous midazolam, a probe for cytochrome P450-3A activity: comparison with grapefruit juice. J Clin Pharmacol. 47: 286294.

Frappier S., Breilh D., Diarte E., Ba B., Ducint D., Pellegrin JL., Saux MC., 1998. Simultaneous determination of ritonavir and saquinavir, two human immunodeficiency virus protease inhibitors, in human serum by highperformance liquid chromatography. Journal of Chromatography B. 714: 384-389.

Genser D., 2008. Food and drug interaction: consequence for the nutrition/health status. Ann Nutr Metab. 52: S29-S32.

Hall SD., Thummel KE., Watkins PB., Lown KS., Benet LZ., Paine MF., Mayo RR., Turgeon DK., Bailey DG., Fontana RJ., 1999. Molecular and physical mechanisms of first-pass extraction. Drug Metab Dispos. 27: 161-166.

Harumi Y., Hajime K., Tetsuya N., Aikichi I., 2001. Simultaneous determination of the 
HIV protease inhibitors indinavir, amprenavir, saquinavir, ritonavir and nelfinavir in human plasma by highperformance liquid chromatography. Journal of Chromatography B. 755: 85-89.

Hidaka M., Okumura M., Fujita K., 2005. Effects of pomegranate juice on human cytochrome p450 3A (CYP3A) and carbamazepine pharmacokinetics in rats. Drug Metab Dispos. 33: 644-648.

Ho RH., Kim RB., 2005. Transporters and drug therapy: implications for drug disposition and disease. Clin Pharmacol Ther. 78: 260-277.

Holladay JW., Dewey MJ., Michniak BB., Wiltshire H., Halberg DL., Weigl P., Liang Z., Halifax K., Lindup WE., Back DJ., 2001. Elevated $\alpha 1$-acid glycoprotein reduces the volume of distribution and systemic clearance of saquinavir. Drug Metab Dispos. 29: 299-303.

Huang SM., Strong JM., Zhang L., Reynolds KS., Nallani S., Temple R., 2008. New era in drug interaction evaluation: US Food and Drug Administration update on CYP enzymes, transporters, and the guidance process. J Clin Pharmacol. 48: 662-670.

Huy RH., Ferenc F., Yvonne B., Stephan K., 1997. Determination of saquinavir in human plasma by high-performance liquid chromatography. Journal of Chromatography B. 694: 427-433.

Joseph TD., Robert LT., Gary CY., Gary RM., Barbara GW., Michael PL., 2008. Pharmacotherapy A Pathophysiologic Approach. New York: McGraw-Hill Medical, United States of America.

Jurenka JS., 2008. Therapeutic applications of pomegranate (Punica granatum L.): a review. Altern Med Rev. 13: 128-144.

Kenneth ET., Kent LK., Danny DS., 1997. Enzyme-catalyzed processes of first-pass hepatic and intestinal drug extraction. Advanced Drug Delivery Reviews. 27: 99-127.

Krueger DA., 2012. Composition of pomegranate juice. J AOAC Int. 95 (1): 163-168.

Kupferschmidt HH., Fattinger KE., Ha HR., Follath F., Krahenbuhl S., 1998. Grapefruit juice enhances the bioavailability of the HIV protease inhibitor saquinavir in man. $\mathrm{Br} J$ Clin Pharmacol. 45: 355-359.

Lansky EP., Newman RA., 2007. Punica granatum (pomegranate) and its potential for prevention and treatment of inflammation and cancer. $J$ Ethnopharmacol. 109: 177-206.

Lee CG., Gottesman MM., Cardarelli CO., 1998. HIV-1 protease inhibitors are substrates for the MDR1 multidrug transporter. Biochemistry. 37: 3594-3601.

Letendre L., Scott M., Dobson G., Hidalgo I., Aungst B., 2004. Evaluating barriers to bioavailability in vivo: validation of a technique for separately assessing gastrointestinal absorption and hepatic extraction. Pharmaceutical Research. 21: 1457-1462.

Martin FM., Burhenne J., Ding R., 2002. Dosedependent increase of saquinavir bioavailability by the pharmaceutic aid cremophor EL. British Journal of Clinical Pharmacology. 53: 576-581.

Michael DS., Melanie EE., Gerdi W., Jennifer JD., Mailine HC., Ruth M., Caren JR., 2005. Effects of Pomegranate Juice Consumption on Myocardial Perfusion in Patients With Coronary Heart Disease. The American Journal of Cardiology. 96; 810-814.

Muneaki H., Manabu O., Kenichi F., Tetsuya O., Keishi Y., Tomomi I., Nao S., Kazuhiko A., 2005. Effects of pomegranate juice on human cytochrome p450 3a (cyp3a) and carbamazepine pharmacokinetics in rats. Drug metabolism and disposition. 33: 644648.

Nagata M, Hidaka M,, Sekiya H., 2002. Effects of pomegranate juice on human cytochrome P450 2C9 and tolbutamide pharmacokinetics in rats. Drug Metab Dispos. 35: 302-305.

Neirinckx E., Vervaet C., De Boever S., Remon JP., Gommeren K., Daminet S., De Backer P., Croubels S., 2010. Species comparison of oral bioavailability, firstpass metabolism and pharmacokinetics of acetaminophen. Research in Veterinary Science. 89: 113-119. 
Neurath AR., Strick N., Li YY., Debnath AK., 2005. Punica granatum(pomegranate) juice provides an HIV-1 entry inhibitor and candidate topical microbicide. Ann N Y Acad Sci. 1056: 311-327.

Noble S., Faulds D., 1996. Saquinavir. A review of its pharmacology and clinical potential in the management of HIV infection. Drugs. 52: 93-112.

Paine MF., Hart HL., Ludington SS., Haining RL., Rettie AE., Zeldin DC., 2006. The human intestinal cytochrome P450 "pie". Drug Metab Dispos. 34: 880-886.

Paine MF., Khalighi M., Fisher JM., Shen DD., Kunze KL., Marsh CL., Perkins JD., Thummel KE., 1997. Characterization of interintestinal and intraintestinal variations in human CYP3A-dependent metabolism. J Pharmacol Exp Ther. 283: 1552-1562.

Ravindra BP., Naveen BK., Haroled PL., Rajesh K., Jawahar BP., 2013. Influence of quercetin on the pharmacokinetics of ranolazine in rats and in vitro models. Drug Development and Industrial Pharmacy. 39: 873-879.

Shih HF., Yu CH., Pei DLC., 2005. Pharmacokinetic and pharmacodynamic interactions of morin and cyclosporine. Toxicology and Applied Pharmacology. 205: 65-70.

Shravan KY., Adukondalu D., Bhargavi LA., Vamshi VY., Ramesh G., Shiva KR., Madhusudan RY., Sarangapani M., 2011. Effect of pomegranate pretreatment on the oral bioavailability of buspirone in male albino rabbits. Daru. 19: 266-269.

Shriram MP., Ranjith KA., Subramanian G., Udupa N., 2007. Development and validation of a reversed-phase liquid chromatographic method with fluorescence detection for the study of Saquinavir pharmacokinetics in rat plasma. Analytica Chimica Acta. 594: 248256.
Sridhar V., Surya SM., Ravindra BP., Naveen BK., 2014. Evaluation of First-Pass Cytochrome P4503A (CYP3A) and Pglycoprotein Activities Using Felodipine and Hesperetin in Combination in Wistar Rats and Everted Rat Gut Sacs in Vitro. Phytother. Res. 28: 699-705.

Stephane JM., Mary FP., Paul BW., 2004. Contributions of CYP3A4, Pglycoprotein, and Serum Protein Binding to the Intestinal First-Pass Extraction of Saquinavir. The journal of pharmacology and experimental therapeutics. 308: 941-948.

Swathi V., Shravan KY., Shiva KR., Ramesh G., Madhusudan RY., 2012. Effect of Pomegranate Juice on Intestinal Transport and Pharmacokinetics of Nitrendipine in Rats. Phytother. Res. 26: 1240-1245.

Undevia SD., Gomez AG., Ratain MJ., 2005. Pharmacokinetic variability of anticancer agents. Nat Rev Cancer. 5: 447-458.

Wacher VJ., Silverman JA., Zhang Y., Benet LZ., 1998. Role of P-glycoprotein and cytochrome $\mathrm{P} 4503 \mathrm{~A}$ in limiting oral absorption of peptides and peptidomimetics. J Pharm Sci. 87: 13221330.

Wahajuddin., Raju KS., Singh SP., Taneja I., 2014. Investigation of the functional role of P-glycoprotein in limiting the oral bioavailability of lumefantrine. Antimicrob Agents Chemother. 58: 489-494.

Williams PEO., Muirhead GJ., Madigan MJ., Mitchell AM., Shaw T., 1992. Disposition and bioavailability of the HIV-proteinase inhibitor, Ro 31-8959, after single doses in healthy volunteers. Br J Clin Pharmacol. 34:155P-156P.

Yang J., Jamei M., Yeo KR., Tucker GT., Rostami HA., 2007. Prediction of intestinal first-pass drug metabolism. Curr Drug Metab. 8: 676-84. 